\title{
O turismo e as implicações ambientais nas localidades de Arembepe e Imbassaí no Litoral Norte da Bahia
}

\author{
Maria Tuanne Brito Silva ${ }^{1}$; Telma Maria Sousa dos Santos ${ }^{2}$ \\ 1. Bolsista PIBIC/FAPESB, Graduando em Geografia, Universidade Estadual de \\ Feira de Santana, e-mail: Mari-any@hotmail.com \\ 2. Orientador, Departamento de Ciências Humanas e Filosofia, Universidade Estadual \\ de Feira de Santana, e-mail: Telmaarq@yahoo.com.br
}

PALAVRAS-CHAVE: Turismo, Planejamento, Urbanização e Meio Ambiente

\section{INTRODUÇÃO}

O turismo é hoje uma importante atividade econômica e assim como diversas outras infligem danos ao meio ambiente. $\mathrm{O}$ uso dos recursos naturais; o transito intenso de pessoas; a ocupação de áreas de proteção ambiental para a construção de segundas residências, moradias e equipamentos turísticos (como hotéis, bares, restaurantes e ressortes); a ausência de esgotamento sanitário adequado, o aumento dos resíduos sólidos; a contaminação das águas dos rios e mares em função do despejo do esgoto não tratado; o aumento da utilização da água potável; do tráfego de veículos; a alteração da paisagem por conta da construção de edifícios e equipamentos inadequados são fatores que tem gerado agressões ao meio ambiente a partir da inserção da atividade turística nos espaços receptores.

Um outro fator de grande impacto ao meio ambiente é a urbanização decorrente da implantação de obras de infraestrutura para a adequação dos espaços para o funcionamento da atividade turística, estas causam diversos impactos negativos como a abertura de estradas que ocasionam o atropelamento de animais que vivem aos arredores, pavimentação de vias que dificultam o escoamento da água para o subsolo, aterros para a realização de construções, instalação de equipamentos turísticos dentre outros. A urbanização é uma tendência para as áreas turísticas principalmente nas litorâneas, isto porque na atualidade os interesses do poder público e das entidades privadas estão voltados para essas áreas que dispõem de um vasto potencial de recursos naturais. Desse modo, o que se busca é adequação desses lugares para o turismo que é visto como uma atividade favorável ao crescimento econômico.

No entanto é importante ressaltar que a atividade turística quando realizada de forma predatória sem o devido controle e planejamento pode gerar impactos sobre o meio ambiente, nessa perspectiva é necessário buscar o equilíbrio entre os interesses econômicos, sociais e ambientais. Desse modo, esta pesquisa teve por objetivo geral analisar as implicações ambientais decorrentes do processo de urbanização nas localidades de Arembepe e Imbassaí no Litoral Norte da Bahia. A área estudada passou por um intenso processo de urbanização e requalificação urbanística a partir de 
investimentos do poder público, as ações realizadas contribuíram para a valorização desses espaços para o turismo, bem como, influenciaram a ocupação dessas áreas e o surgimento problemas ambientais.

\section{PROCEDIMENTOS METODOLÓGICOS}

Inicialmente foi realizado um levantamento bibliográfico para a construção do embasamento teórico que norteou o desenvolvimento do trabalho. Em seguida em gabinete foi efetivado a coleta de dados secundários através de revistas, teses, dissertações, artigos, sites e materiais existentes no banco de dados do Grupo de Pesquisa em Espaço Turismo e Meio Ambiente (GETAM). Como próximo passo para o desenvolvimento da pesquisa foi feita a coleta de imagens no Google Earth do satélite CNE/Astrium dos anos de 2002, 2016 e 2017, elas foram utilizadas para espacializar as áreas de pressão ambiental nas localidades estudadas, utilizou-se a ferramenta adicionar polígono para delimitar as áreas de lagoas ocupação de dunas e concentração de construções. Como não houve a realização das visitas de campo para identificar as áreas que vem sofrendo pressão ambiental nas localidades estudas e os agentes que tem promovido tal situação utilizou-se dados que foram coletados durante outras visitas de campo realizadas nos anos de 2015 e 2016. Após a coleta dos dados e informações realizou-se a sistematização e a produção dos resultados finais da pesquisa.

\section{RESULTADOS E DISCUSSÕES}

Para analisar as alterações ambientais ocasionadas pela ação humana (poder público e população visitante e residente) nas localidades estudadas utilizou-se nesse trabalho os indicadores ambientais, a partir deles é possível identificar e descrever as pressões exercidas sobre os recursos naturais. O modelo PER Pressão-Estado-Resposta tem sido amplamente utilizado na produção de estudos acerca da degradação ambiental, a pressão corresponde as atividades humanas que causam a destruição do meio ambiente, o estado mostra as condições do ambiente que está sofrendo pressão ambiental e a resposta consiste nas medidas implementadas para reduzir ou sanar a degradação. Esse modelo conceitual apresenta vantagens por conta da sua simplicidade e eficácia para o monitoramento das pressões sobre o ambiente.

A localidade de Arembepe apresenta uma ocupação urbana bastante antiga que ocorreu de forma não planejada, acarretando no surgimento de diversos problemas ambientais. O desenvolvimento da atividade turística influenciou a expansão urbana pela qual a localidade passou nas últimas décadas, isso porque a localidade tornou-se mais atrativa para pessoas que desejam praticar o lazer em seu tempo livre. Por ter um potencial turístico elevado e pela grande procura de veranistas, a localidade recebeu uma serie de investimentos por parte do poder público através da elaboração e execução do projeto de requalificação urbanística que ocorreu entre os anos de 2011 a 2012. As ações interventivas contribuíram para reconfigurar a paisagem do centro urbano da localidade a partir da instalação de diversos equipamentos que contribuíram para tornar a infraestrutura urbana e turística mais adequada para os visitantes. 
Durante o desenvolvimento da pesquisa foi possível identificar alguns pontos de pressão ambiental na localidade que são o reflexo da ocupação não planejada, percebe-se que muitos indivíduos ocuparam áreas ambientalmente frágeis ocasionando em desequilíbrios ambientais. No áreas loteamento Fonte das Águas um dos mais antigos da localidade em função da ausência do esgotamento sanitário é possível perceber esgoto correndo a céu aberto em muitas ruas, o que pode contribuir para a poluição difusa uma vez que resíduos podem ser arrastados em direção aos recursos hídricos, no loteamento é possível notar a presença de uma ocupação irregular situada em uma área de dunas que fica em torno de uma lagoa que se encontra bastante poluída por conta do esgoto doméstico que é lançado diretamente no local sem nenhum tratamento, o odor é bastante forte e a visibilidade da água encontra-se comprometida por conta da presença de uma vegetação densa dentro da lagoa, sobre essa questão o poder Público Municipal afirmou que tem conhecimento da ocupação da área e que está avaliando formas de solucionar o problema.

O loteamento Caraúna assim como o Fonte das águas encontra-se localizado em uma área ambientalmente frágil, o mesmo encontra-se circundado por lagoas, boa parte delas foram aterradas para a construção de casas e até mesmo por obras desenvolvidas pelo poder público municipal. Por ser uma área de lagoas algumas ruas do loteamento ficam cobertas por água e não secam nem mesmo nos períodos mais quentes com baixa pluviosidade. Esse problema é reflexo da ocupação irregular gerada através da expansão urbana não planejada de Arembepe, de acordo com o poder público ainda não foi pensado nenhuma ação para sanar esse problema. Outro problema observado é o descarte de lixo nos terrenos baldios o que compromete o solo, ausência do esgotamento sanitário e despejo de esgoto sem tratamento nas áreas de lagoa. Na porção oeste da localidade outra área de dunas vem sendo ocupada por residências que aparentemente estão em processo de construção o que evidencia que a ocupação da área é recente, no local também percebese o descarte irregular de lixo e entulho proveniente das construções que estão em curso.

No que se refere a Imbassaí, a localidade passou por um intenso processo de transformação do seu espaço a partir da execução do projeto de urbanização que foi elaborado pela prefeitura de Mata de São João em parceria com o governo do estado da Bahia. A urbanização contribuiu par aumentar o fluxo de turistas na localidade e para inserir a localidade de Imbassaí no Panorama turístico do município de Mata de São João no estado da Bahia. As modificações realizadas na localidade promoveram uma intensa alteração do espaço natural da localidade, verifica-se que a cobertura vegetal foi retirada em muitos pontos para dar lugar as construções.

É possível perceber que a expansão da atividade turística tem contribuído para uma intensa ocupação do solo da área central da localidade de Imbassaí e dos loteamentos que se encontram mais afastados da linha de praia por uma população de baixo poder aquisitivo que vem sendo atraída para a região. A medida que a ocupação se intensifica surge também agressões ao meio ambiente, no decorrer do desenvolvimento da pesquisa identificou-se algumas áreas na localidade que vem sofrendo pressão ambiental. A primeira está inserida dentro do loteamento Jardim Imbassaí, trata-se da ocupação de uma área de preservação ambiental, as construções foram derrubadas pelo poder público municipal em uma ação realizada no ano de 2015. Outro problema identificado no 
loteamento relaciona-se a um riacho que corta a área, existem construções bem próximas as suas margens, a retirada da cobertura vegetal pode ocasionar o assoreamento do canal por conta do acumulo de sedimentos e a erosão das margem do canal uma vez que o solo exposto é mais vulnerável a erosão pluvial. É possível observar ainda que o curso do riacho foi alterado pela população que colocou sacos de areia para formar uma piscina natural utilizada por eles para o lazer.

Um dos pontos mais preocupantes em Imbassaí é a ausência do esgotamento sanitário na maior parte da localidade, a expansão urbana tem gerado a poluição dos recursos hídricos como o rio Imbassaí que é um dos principais atrativos da localidade. É importante que uma atenção maior seja dada para essas problemáticas ambientais uma vez que os principais atrativos turísticos da localidade acabam ficando ameaçados o que pode comprometer o funcionamento da atividade turística e a perca da qualidade de vida da comunidade local.

\section{CONSIDERAÇÕES FINAIS}

A partir dos desenvolvimento da pesquisa foi possível perceber que as localidades de Arembepe e Imbassaí passaram por modificações em seus espaços para se inserir dentro do novo panorama criado para o Litoral Norte da Bahia. As ações realizadas pelo poder público contribuíram para a expansão da atividade turística e consequentemente para a intensificação da ocupação do solo das localidades, no entanto percebe-se que a medida que isso acontece se intensifica o surgimento de problemas ambientais. Embora ambas as localidades estejam inseridas em Áreas de Proteção Ambiental APA/Litoral Norte, a legislação vem sendo descumprida e o poder público negligencia muitas vezes a fiscalização e a inibição da ocupação de áreas destinadas a preservação. Grande parte das pressões ambientais identificadas são causadas pelos próprios moradores o que evidencia a ausência de uma educação ambiental. Para que o turismo se desenvolva de forma sustentável é necessário fortalecer o trabalho de educação ambiental nas comunidades e com os turistas para que os mesmos compreendam que a conservação dos recursos é essencial para a continuidade dessa prática, além disso o crescimento urbano deve ser controlado pelo poder público para que não venha surgir mais problemas ambientais.

\section{REFERÊNCIAS}

Carvalho, Paulo Gonzaga Mibielli de, et. Al. Indicadores para a avaliação da gestão ambiental municipal com base no modelo Pressão-Estado-Resposta. Caxambú-MG, 2008.

CRUZ, Rita de C. A. Introdução a Geografia do Turismo. São Paulo/SP: Roca, 2003.

SANTOS, Telma Maria Sousa dos. Turismo e urbanização em espaços litorâneos: um olhar sobre Praia do Forte-Bahia. Feira de Santana: UEFS, 2013.

QUEIROZ, Lucia Aquino de. Turismo na Bahia: estratégias para o desenvolvimento. Salvador: Secretaria da Cultura e Turismo, 2002.

REJOWSKI, Mirian. Turismo no percurso do tempo. 2. Ed. São Paulo/AP: Aleph, 2002. 